\title{
Implementation of a prosthetic labelling process in implant-supported fixed prosthesis and comparison of two different methods: an in vitro study
}

\author{
Hasan Akbaba', Mustafa Zortuk ${ }^{2^{*}}$ (D) and Haydar Albayrak ${ }^{3}$
}

\begin{abstract}
Background: This study is to compare the two different techniques used in the labeling of implant-based fixed prostheses, using the square code and using microchip labeling techniques, taking into account the properties of an ideal prosthetic labeling technique. Sixty implants fixed prostheses were produced, 30 for each group. Square codes were created on the lingual bands of implants fixed prostheses which are the samples of the group that were labelled by using square code, and microchips were placed in the implant abutments of the samples in the group that were labelled with the microchip.
\end{abstract}

Results: The thermal cycle test was used to compare the long-life cycle of the samples, and no deformation was found. A survey attended by 51 dentists was created to evaluate the techniques' effects on their aesthetic appeal and their application. The data found was statistically evaluated, and the result was statistically insignificant $(p<0.05)$.

Conclusions: Microchips' data storage capacity was found more successful; however, according to their resistance to heat and their costs, the square code, was more advantageous.

Keywords: Labelling of dentures, Forensic dentistry, Prosthetic identification, Dental implant

\section{Background}

International dental communities and forensic dentists recommend the labelling of all dentures. Prosthetic labelling practices have been standardised in the USA; the social security number of the individuals is marked on the denture, but this marking is mandatory only in 21 states (Pathak et al. 2018). In addition, the United Kingdom (UK) Alzheimer's Society strongly recommends the labelling of any prostheses made by the Alzheimer's Society of the UK since prosthetic labels contain information on missing prostheses and can be used to identify patients suffering from dementia or who cannot be identified for any reason following death (Pathak et al. 2018; Datta and Sood 2010; Kalyan et al. 2014).

\footnotetext{
* Correspondence: mustafazortuk@gmail.com

${ }^{2}$ Department of Prosthodontics, Faculty of Dentistry, Hatay Mustafa Kemal University, Tayfur Sökmen Kampüsü, 31060 Alahan-Antakya, Hatay, Turkey Full list of author information is available at the end of the article
}

Implant-supported prostheses (ISPs) are becoming increasingly common in the dentistry field. Hundreds of new implant brands emerge every year globally. As such, labelling of dental implants should not be ignored. However, during patient treatment, implant brands or records may not always be available, and access to this information would be convenient for dentists (Kalyan et al. 2014; Richmond and Pretty 2007; Berketa et al. 2010). It would be easy for dentists to access this information through labelling operations on ISPs. Several previous studies that investigated prosthetic labelling focused on the labelling of removable prostheses. However, limited studies have been performed on the labelling of fixed prostheses.

It has become difficult to appreciate all of the different implant brands and systems. Labelling of implant restorations becomes important when the prosthesis requires replacement; impressions are required after many years and parts of the dental implants (analogue, abutment 
screw, etc.) are required in the case of complications. At the same time, Straumann ${ }^{\text {ma }}$ company has been laser etching batch numbers within the chamber of their implants. The number of implants with the same batch number varies between 24 and 2400. Although this number is still quite high, it reduces the frequency from many thousands in some cases (Berketa et al. 2010; Straumann Annual Report 2009).

The aim of this study was to compare two different labelling methods, namely, microchip and square code, which can be used in implant-supported fixed prostheses.

\section{Material and methods}

To study the application of prosthetic labelling in implant-supported fixed prostheses, acrylic models were prepared and implant analogues were generated at Erciyes University, Turkey. For labelling, the phantom jaw model (Frasaco Phantom, Tettnang, Germany) was used.

\section{Sample generation}

A total of 60 implants and analogues were used in our in vitro study. Implant analogues were fixed using a specifically prepared metal mould (Fig. 1). An autopolymerising acrylic resin was poured into the metal mould, and the specimens were numbered. Prepared samples were subsequently transferred to the laboratory where metal-supported porcelain restorations were made for use as a master model. Subsequently, occlusion spray (Occlusion-Spray; Bausch, Cologne, Germany) was applied to the abutment surfaces to improve the quality of scanned images, and the models were scanned using a scanner (Activity 885; Smart Optics, Bochum, Germany). A virtual model of the right lower first molar tooth was created with a 4-mm metal band on the lingual side. Obtained data were transferred to a computer-aided design and computer-aided manufacturing (CAD/CAM) device (Quadro MILL Comfort; Quadro, Ontario, Canada) to generate a hard wax model. The wax model was evaluated, and necessary adjustments were made. Subsequently, metal coping was fabricated using a laser-sintering machine (SLM 125; SLM Solutions, Lübeck, Germany), and the sintering process was completed using a metal sintering machine (PLF 120/5; Protherm Furnaces, Istanbul, Turkey). Next, dental porcelain (Ceramco-Dentsply, Burlington, NJ, USA) was made in the form of the right lower first molar and was glaze-phase finished. Finally, the lingual metal band (4 $\mathrm{mm}$ wide) was polished, and the samples were prepared for laser barcoding.

\section{Preparation of quick response (QR) code labelling}

QR code labelling was performed on the lingual metal band restorations using a laser (TruMark Series 3000;
OTES Electronic, Istanbul, Turkey). The data to be stored in the QR code were generated using the CAD program and Tru Tops Mark (TTM) software of Trumpf. The 'barcode' option was preferred in the CAD program. Under the barcode type option, the $\mathrm{QR}$ code (data matrix) preference was selected. The QR code content included the 11-digit patient citizenship number, and the QR code size information $(3-3 \mathrm{~mm})$ was set (Fig. 2). In the program, we selected metal as the material type, and laser parameters such as power, speed, and frequency were adjusted accordingly.

Following generation of the $\mathrm{QR}$, samples were read using the barcode reader terminal (HCR 6200 DPMMobile 2D-Code Reader; Leuze Electronic, Owen, Germany) to determine whether the recorded data could be accessed.

\section{Preparation of microchip labelling}

Microchips $(2 \times 3 \times 0.75 \mathrm{~mm})$ with a data capacity of $16 \mathrm{~kb}(16,320$ characters $)$ were placed in the prepared samples $(n=30)$ (Fig. 3). Prior to insertion of the microchips in the implant abutment, an imaginary patient's identification, dental records, and medical history were recorded on the microchip. To transfer this data, 'Labelling Program of Fixed Implants Software' and 'USB (Universal Serial Bus) Chip Programmer' hardware were used.

\section{USB chip programmer}

The electronic circuit was designed using the Altium Designer program. The prepared prototype was transferred to an FR4 plate, and fixation was completed at the soldering station (ERSA, Istanbul, Turkey). The prepared circuit was placed in a plastic housing box, HH055. In the USB Chip Scheduler hardware, a control card with a USB 2.0 type B Jack output was used. Computer connection was achieved using a USB type B cable.

\section{Computer software preparation and virtual library creation}

USB Chip Programmer software was developed for Windows X32 and Windows X64 platforms using the Delphi XE7 code development program. After the USB Chip Programmer hardware had been connected to the computer, a microchip was inserted. Information regarding the imaginary patient was entered on both the microchip and the computer.

\section{Cementation of restorations}

Microchips were covered with a Teflon band. Restorations were cemented using polycarboxylate cement (Adhesor Carbofine; Spofa Dental, Prague, Czechia), in accordance with the manufacturer's protocols. Cement 

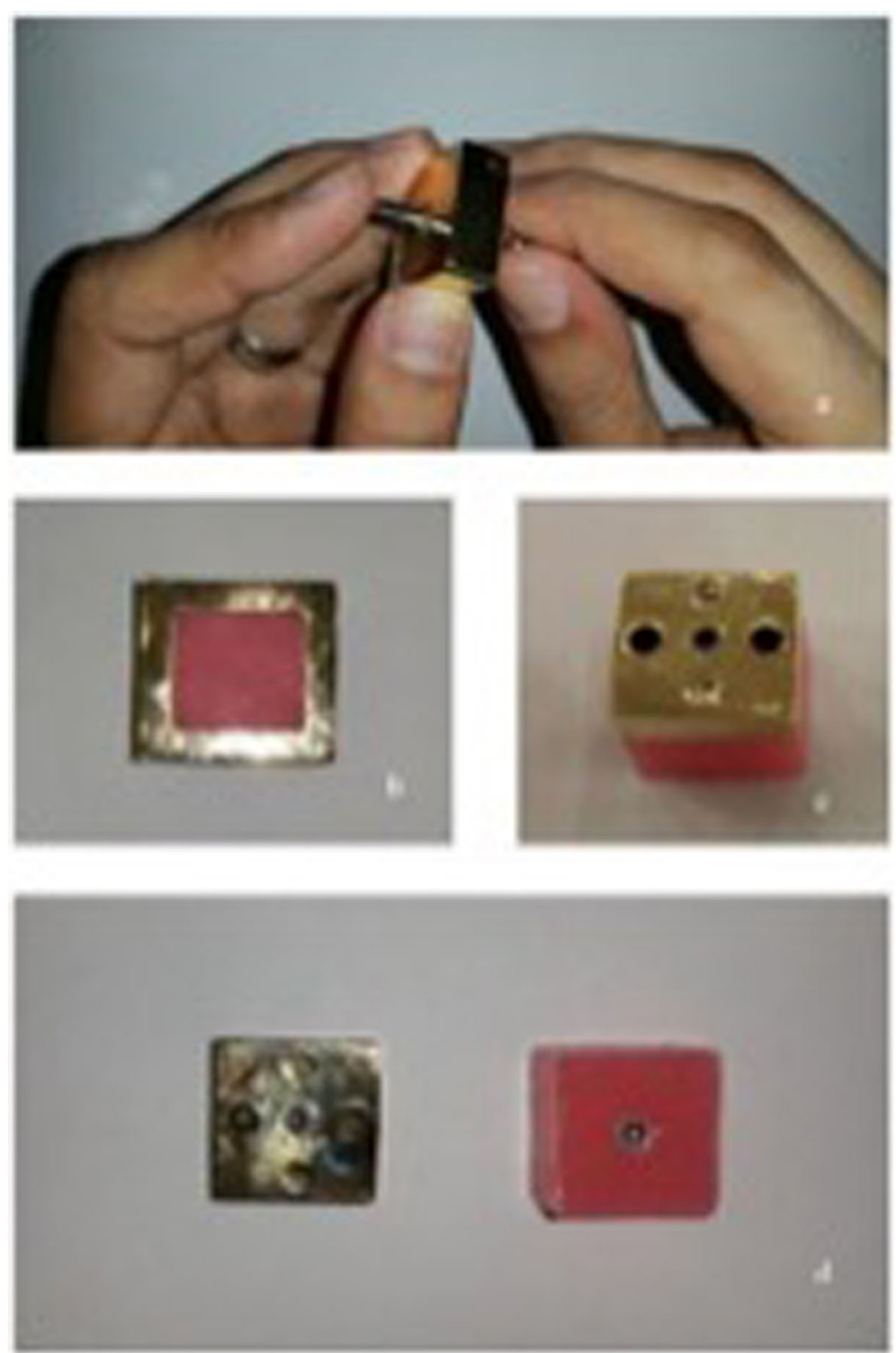

Fig. 1 a Analog placement. b Pouring acrylic into the mould. c Acrylic polymerisation. d Acrylic model

residue was removed following the completion of cement polymerisation.

\section{Evaluation of methods}

A questionnaire was prepared using a visual analogue scale (VAS) to evaluate the effect of both techniques on aesthetic appearance and to compare the applicability of the two techniques. In total, 51 dentists completed this questionnaire.

Samples prepared by labelling with the QR code were subjected to heat exchange at temperatures between $80^{\circ} \mathrm{C}$ and $910^{\circ} \mathrm{C}$, and we explored whether the recorded data could be retrieved. Samples labelled with the microchip were stored at $-40^{\circ} \mathrm{C}$ for $24 \mathrm{~h}$ and then labelled with the QR code for $24 \mathrm{~h}$ at $-80^{\circ} \mathrm{C}$ (Ultra-low $86^{\circ} \mathrm{C}$ Dual Cooling Freezers, MDF-U500VX; Panasonic, Kocintok Laboratory Materials Trade Corporation, Istanbul, Turkey). They were then subjected to high-temperature treatment at $120^{\circ} \mathrm{C}$, and samples labelled using the QR code were subjected to $910^{\circ} \mathrm{C}$.

\section{Thermal cycle test}

Restorations from both groups were subjected to a thermal cycle test. The restoration samples were prepared after the cement residue had been cleaned. Subsequently, they were subjected to the thermal cycle test. 

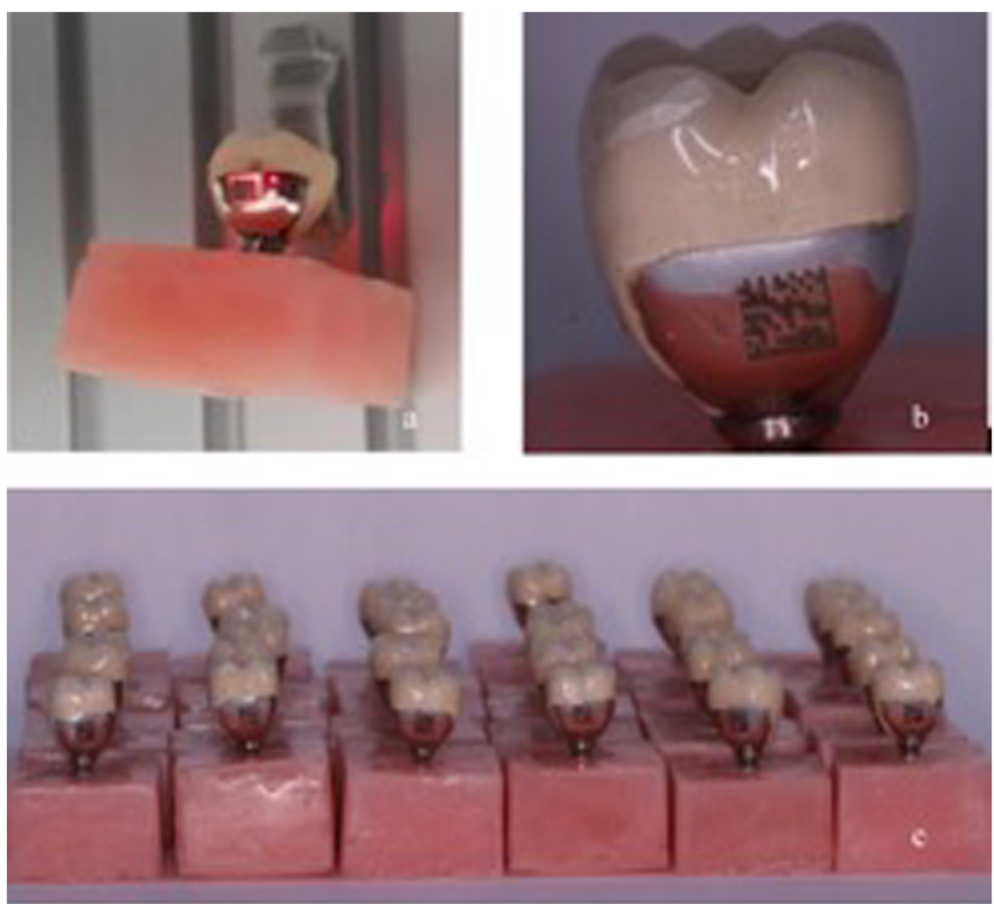

Fig. 2 a Metal ceramic restoration to be labelled, position adjusted. b QR code image. c 30 sample restorations labelled with QR code

This assay was conducted as described previously. The water bath temperature was set between $5{ }^{\circ} \mathrm{C}$ and $55^{\circ} \mathrm{C}$, and samples underwent 2500 hot-cold thermal cycles.

\section{Evaluation of labelling techniques in terms of aesthetics and applicability}

A questionnaire was prepared using a VAS to compare the aesthetics and applicability of the two techniques. In total, 51 dentists completed the questionnaire. Applicability of the techniques, application steps, the effects on aesthetic appearance, and localisation on the restoration were evaluated in the questionnaire.

\section{Statistical evaluation}

The Statistical Package for Social Science (SPSS) program (version 16.0, SPSS Inc., Chicago, IL, USA) was used for statistical analysis in this study. A $p$ value $<0.05$

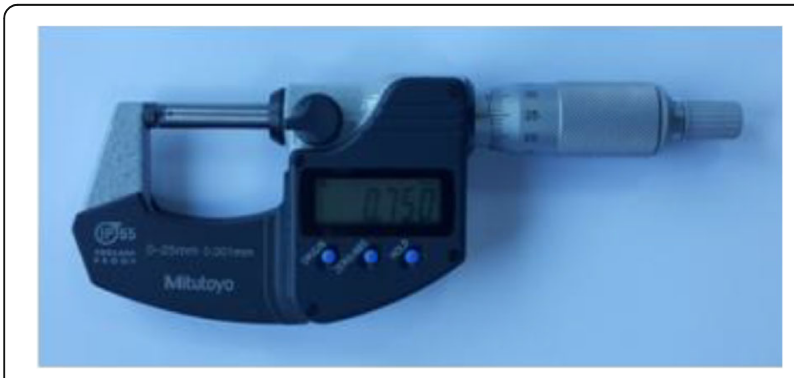

Fig. 3 Control of microchips $(2 \times 3 \times 0.75 \mathrm{~mm})$ was considered statistically significant. Mann-Whitney $U$ tests were used to compare the aesthetic and applicability evaluation results.

\section{Results}

Evaluation of the thermal cycle

A total of 30 specimens labelled with QR codes and 30 specimens labelled with microchips were subjected to a thermal cycling test and subsequently checked to determine whether the recordings were accessible. In each case, data transfer was accessible.

\section{Evaluation of aesthetics}

According to the Mann-Whitney $U$ test, no significant differences were observed between the aesthetic evaluation results for the two techniques (Fig. 4).

\section{Evaluation of feasibility}

According to the Mann-Whitney $U$ test results, no significant differences were observed between the feasibility evaluation results for the two techniques (Fig. 5).

\section{Data storage capacity}

The QR code was generated with $3 \times 3 \mathrm{~mm}$ dimensions, and 11 characters were included in the code. Recorded data were accessed using the QR code reader hand terminal. We created an 11-digit number code because the Republic of Turkey citizenship ID numbers are 11 digits in length. When a database or cloud is created, the 


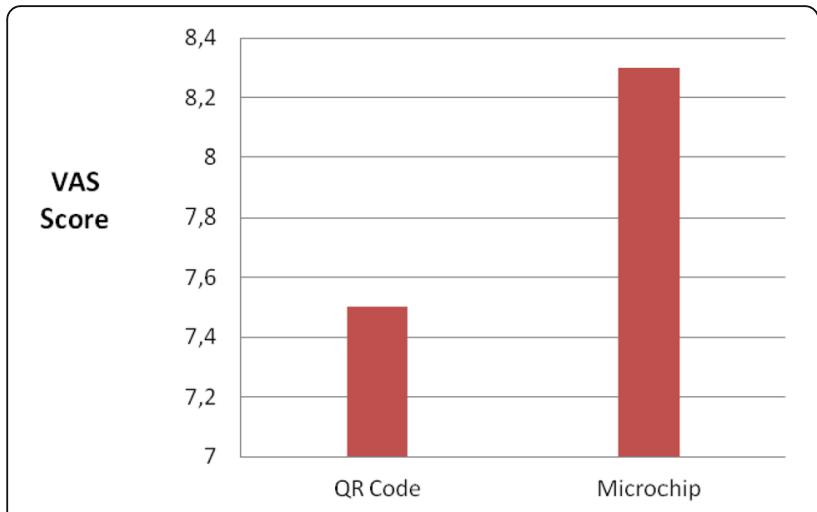

Fig. 4 Aesthetics results of QR code and microchip labeling techniques

information from each patient can be accessed. The storage capacity of the microchips used in our denture labelling was $16 \mathrm{~kb}$. This value allows the dental identification database to store detailed information regarding the identity, dental records, and medical history of a patient, even in the absence of a database.

\section{Thermal resistance}

The microchips used in this study were able to store data damage-free at temperatures between $-40{ }^{\circ} \mathrm{C}$ and $120^{\circ} \mathrm{C}$, and it is possible to retrieve the data as required. Access to QR code data was determined at $-80^{\circ} \mathrm{C}$ for $24 \mathrm{~h}$. QR code integrity was maintained, and data could be retrieved up to a temperature of $910^{\circ} \mathrm{C}$.

\section{Cost evaluation}

The price of each microchip used in our study was $\$ 1.20$, whereas the price of the hardware used to encode data on the microchip or computer software and microchip used for labelling was approximately $\$ 1430$. The total price for the laser, laser counter, and QR code reader terminal was approximately $\$ 28,500$. There are no additional fees for repeated tagging (Table 1).

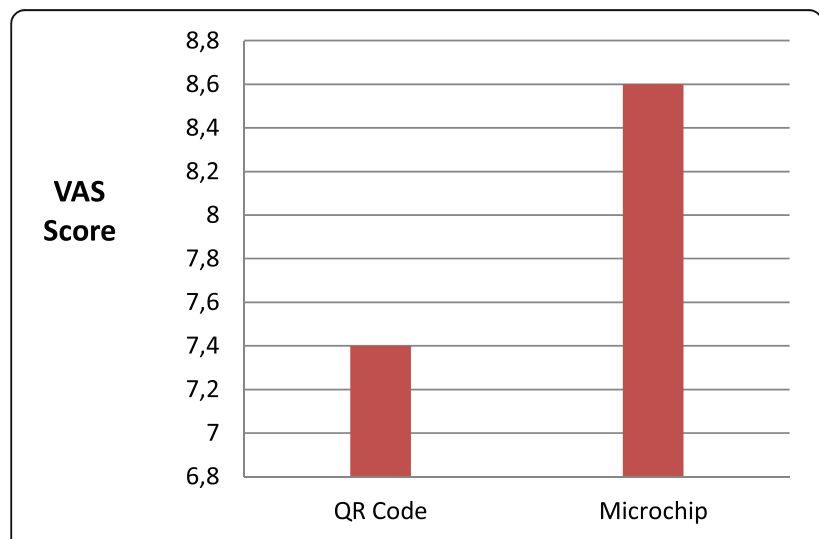

Fig. 5 Feasibility results of QR code and microchip labeling techniques

\section{Discussion}

It is not always possible for patients to store implant or dental company information. However, access to this information would be beneficial to dentists (Mohan et al. 2012). It is possible to acquire this information by labelling implant abutments or crowns. Although several previous studies have explored prosthetic labelling, most have focused on removable dentures. In addition, few studies have investigated the labelling of implantsupported fixed prostheses. In our study, we demonstrate the advantages and disadvantages of labelling implant-supported fixed prostheses using microchip and QR code techniques.

According to the results of the thermal cycle tests, the microchips used for labelling can protect the stored data as long as there is no mechanical or thermal trauma or liquid contamination. Furthermore, the manufacturer states that data uploading/deleting can be performed up to 1000 times safely. One of the disadvantages of this technique is that dentists or dental technicians that wish to label using this technique require the computer hardware and software discussed in our study. Another limitation of this technique is that it must be performed carefully to prevent liquid contamination. However, the use of microchips allows the stored data to be modified or new information to be added. This method, which has been used to label implant-supported fixed dentures, can also be used to label removable dentures. Microchips can be placed in a protective capsule and inserted in an area that is not visible. Advantages of this labelling technique include a data storage capacity of $16,000 \mathrm{~kb}$, which is sufficient to store all information regarding a patient's dental and medical histories, as well as information regarding the physician. The microchips used in our studies do not undergo deformation in the range from $40{ }^{\circ} \mathrm{C}$ to $120^{\circ} \mathrm{C}$, as recommended by the manufacturer. In addition, the microchips will not resist fire when used for labelling of a removable prosthesis, although the restoration, cement, and abutment may have an insulating effect by increasing heat resistance. There will likely be negative effects on the structural integrity of the prosthesis since the microchips are located within the dental implant abutment. However, the advantage of this technique is that it will not affect plaque retention since it is isolated from the oral environment. However, further studies are required to assess bioaccumulation, patients' expectations, and aesthetic views, which can be demonstrated within the limitations of our study (Clement et al. 2006; Stavrianos et al. 2007).

We also applied the QR code in this study. Labelling of the restoration using lasers is performed on the bracelet of metal-supported porcelain restorations. Porcelain material can also be labelled, but because of porcelain complications, it may not be possible to read the square code. Thus, the 
Table 1 Comparison of frame code and microchip labeling techniques in terms of features required in an ideal prosthetic labeling technique

\begin{tabular}{|c|c|c|}
\hline Definition & QR code & Microchip \\
\hline Longevity & $\begin{array}{l}\text { The life of the label is } \\
\text { directly proportional } \\
\text { to the life of the } \\
\text { material being labelled }\end{array}$ & $\begin{array}{l}\text { Thermal cycle test } \\
\text { successful }\end{array}$ \\
\hline Aesthetic & acceptable & Very good \\
\hline Feasibility & Applicable & Applicable \\
\hline $\begin{array}{l}\text { Data storage } \\
\text { capacity }\end{array}$ & $\begin{array}{l}\text { In } 3 \text { mm-3 mm sizes, } 11 \\
\text { characters can be stored } \\
\text { (Internet storage can be } \\
\text { use via QR code link) }\end{array}$ & 16,000 characters \\
\hline Resistance to heat & $\begin{array}{l}\text { Depending on the material } \\
\text { being labelled }\end{array}$ & $-40 / 120^{\circ} \mathrm{C}$ \\
\hline Cost & $\begin{array}{l}\text { Required software and } \\
\text { hardware }=\$ 28.571\end{array}$ & $\begin{array}{l}\text { Required software and } \\
\text { hardware }=\$ 1428, \$ 1.5 \\
\text { for each labelling }\end{array}$ \\
\hline Unity & Very good & Very good \\
\hline Biocompatibility & $\begin{array}{l}\text { Further studies are } \\
\text { necessary }\end{array}$ & $\begin{array}{l}\text { Further studies are } \\
\text { necessary }\end{array}$ \\
\hline Surface roughness & No changes & No changes \\
\hline
\end{tabular}

metal bracelet of metal-supported porcelain restoration was prepared for the QR code. In our report, we preferred to use the QR code in laser colouring mode to avoid any change in surface roughness. The labelled surfaces of the restorations were examined using a profilometer to confirm that there was no change in surface roughness. When labelling with a QR code, it can be written on the desired surface of the restoration and labelled by a technician. If the labelling is performed incorrectly, the metal surface may be polished again and labelled, but it is important to note that repetitive applications will decrease metal thickness. There is no need to remove the restoration when you want to access the recorded data. Recorded data can easily be accessed using an in-mouth camera with code-reading capability. The size of the data to be recorded varies inversely with the resolution when the size of the label is fixed. In our study, 11-digit numerical data were recorded. Even if the data storage capacity appears small, a database can be created, and when a number is assigned to each patient, all desired data can be recorded and easily accessed. When labelling is completed using the QR code, the heat resistance of the technique depends on the material. In this study, Cr-Co alloy was used for metal-supported porcelain samples (Liao and Lee 2010; Okazaki et al. 2012). Another advantage of using the $\mathrm{QR}$ code is it can be easily read by a smart phone. And also, the storage capacity of them becomes almost infinite when what is encoded is linked to a web database with access to information about images, videos, etc. (and not just an identification number). In the future, a very small $\mathrm{QR}$ code can be scanned to access the information via internet.

\section{Conclusions}

Implant applications play an important role in dentistry. Labelling using QR code and microchips are two different techniques with specific advantages and disadvantages. When the financial situation is assessed, although labelling using microchips may appear more economical in the short term, long-term laser labelling will be more economical (Agüloğlu et al. 2009). However, further studies are required to evaluate the biocompatibility.

\section{Abbreviations \\ CAD/CAM: Computer-aided design / Computer-aided manufacturing; ISPs: Implant-supported prostheses; QR: Quick response; SPSS: Statistical Package for Social Science; UK: United Kingdom; VAS: Visual analogue scale}

\section{Acknowledgements}

This study supported by Erciyes University Scientific Research Projects Coordination Unit (Project No. TDK-2016-4948).

\section{Funding}

This study supported by Project No. TDK-2016-4948 by Erciyes University Scientific Research Projects Coordination Unit.

Availability of data and materials

Authors accepted to share their data of this article.

\section{Authors' contributions}

In this project, HAk is the research assistant, MZ is the scientific adviser, and $\mathrm{HAl}$ is the English consultant. All authors read and approved the final manuscript.

Ethics approval and consent to participate

Manuscripts reporting studies has not involving human participants, human data, or human tissue.

\section{Consent for publication}

Our manuscript has not contained any individual person's data in any form (including individual details, images or videos).

\section{Competing interests}

The authors declare that they have no competing interests.

\section{Publisher's Note}

Springer Nature remains neutral with regard to jurisdictional claims in published maps and institutional affiliations.

\section{Author details}

${ }^{1}$ Kayseri Nimet Bayraktar Oral and Dental Health Hospital, Kayseri, Turkey. ${ }^{2}$ Department of Prosthodontics, Faculty of Dentistry, Hatay Mustafa Kemal University, Tayfur Sökmen Kampüsü, 31060 Alahan-Antakya, Hatay, Turkey. ${ }^{3}$ Department of Prosthodontics, Faculty of Dentistry, Erciyes University, Kayseri, Turkey.

Received: 26 March 2018 Accepted: 28 November 2018 Published online: 13 December 2018

\section{References}

Agüloğlu S, Zortuk M, Beydemir K (2009) Denture barcoding: a new horizon. Br Dent J 206:589-590

Berketa J, James H, Marino V (2010) Survival of batch numbers within dental implants following incineration as an aid to identification. J Forensic Odontostomatol 28(1):1-4

Clement JG, Winship V, Ceddia J, Al-Amad S, Morales A, Hill AJ (2006) New software for computer-assisted dental-data matching in disaster victim identification and long-term missing persons investigations: "DAVID web". Forensic Sci Int 159(Suppl 1):S24-S29

Datta P, Sood S (2010) The various methods and benefits of denture labeling. J Forensic Dent Sci 2:53-58 
Kalyan A, Clark RKF, Radford DR (2014) Denture identification marking should be standard practice. Br Dent J 216:615-617

Liao K-C, Lee W-H (2010) A novel user authentication scheme based on QR-code. J Networks 5:937-941

Mohan J, Dhinesh Kumar CD, Simon P (2012) "Denture marking" as an aid to forensic identification. J Indian Prosthodont Soc 12:131-136

Okazaki S, Li H, Hirose M (2012) Benchmarking the use of QR code in mobile promotion: three studies in Japan. J Advert Res 52:102-117

Pathak C, PAwah S, Sikri A, Rao I (2018) Unique denture identification system for all Indian natioanls. Contemp Clin Dent 9:185-188

Richmond R, Pretty IA (2007) Denture marking--patient preference of various methods. J Forensic Sci 52(6):1338-1342

Stavrianos C, Stavrianou I, Kafas P (2007) Denture identification system based on Swedish guidelines: a forensic aspect. Internet J Forensic Sci 3:1-8

Straumann Annual Report 2009. [Internet].[cited 2010 Oct 6]; Available from: www.straumann.com/com-index/com-investorrelations.htm

\section{Submit your manuscript to a SpringerOpen ${ }^{\circ}$ journal and benefit from:}

- Convenient online submission

- Rigorous peer review

- Open access: articles freely available online

- High visibility within the field

- Retaining the copyright to your article

Submit your next manuscript at $\boldsymbol{\nabla}$ springeropen.com 